\title{
Mathematical Model of Dispersed Coal Layer Ignition by the Penetrated Local Heating Source
}

\author{
Dmitrii Glushkov ${ }^{1, \text { a) }}$, Maxim Glotov ${ }^{1, \text { b) }}$ and Kristina Paushkina ${ }^{1, \mathrm{c})}$ \\ ${ }^{1}$ National Research Tomsk Polytechnic University, 634050 Tomsk, Russia. \\ a)Corresponding author: dmitriyog@tpu.ru \\ b)max.glotov2018@yandex.ru \\ c)kkp1@tpu.ru
}

\begin{abstract}
This article presents a theoretical study devoted to the gas-phase ignition of dispersed brown coal layer by a metal particle heated to high temperatures (more than $1000 \mathrm{~K}$ ) in the framework of a mathematical model describing the interrelated processes of coal heating, cooling of a local heating source, thermal decomposition of solid fossil fuel, the yield of volatile fluxes, the formation and heating of a gas mixture, its ignition. The influence of the heating source initial temperature and the depth of its penetration into the coal near-surface layer on the main process characteristic - the ignition delay time - was established. The relationship between the position of the combustion initiation zone in the hot particle neighbourhood and the heating intensity of the gas mixture including the thermal decomposition products of coal and an oxidizer was revealed.
\end{abstract}

\section{INTRODUCTION}

Dispersed coals (particle size is from several micrometers to several millimeters) are characterized by relatively high chemical activity during the air oxidation $[1,2]$. Due to the widespread use of coal as a fuel for thermal power plants and boiler houses [3] or as raw materials [4] in a number of industries, the actual task is to study the laws and characteristics of its ignition. Quite a large number of works are devoted to the study of the processes of solid fossil fuel spontaneous combustion [5-7] or its ignition by conductive heating by massive heat sources, for example, by heated walls of technological equipment $[8,9]$, the temperature of which, as a rule, is constant for a long period of time. At the same time, depending on the state of environment or heating characteristics, the induction period duration can be from several minutes to several days [7-9].

The processes of combustion initiation of the dispersed coal layer under the conditions of local conductive heating by hot particles of small size $[10,11]$ occur more intensively. Owing to the particle cooling due to the heat removal into the dispersed fossil fuel and gas environment [12-15], the induction period duration in a certain range of initial source temperatures is several seconds, if the heat flow rate towards the ignition zone is sufficient to initiate combustion.

As a rule, dispersed coal has a loose structure, so the interaction conditions of the local heating source with the fuel in such a state can have a significant impact on the process intensity [15]. At the same time, there are three most typical variants of heat transfer conditions to fuel and the surrounding gas environment: the hot particle is located on the surface of coal layer, it is partially or completely penetrated in its near-surface layer.

The aim of this work is to study the laws and characteristics of ignition of typical dispersed solid fuel by a particle heated to high temperatures in the framework of a model, taking into account the penetration of this particle into the near-surface layer of coal. 


\section{PROBLEM STATEMENT}

The axisymmetric problem of coal ignition by a heated particle in the disk form of the sizes $r_{p}$ and $z_{p}$ is solved in a cylindrical coordinate system (Fig. 1). The object of the study is a typical 2B brown coal, which has similar thermal properties to the energy coals [16] of Kuznetsk and Kansk-Achinsk basins in Russia, as well as to Shive-Ovooskoye Deposit of Mongolia. Three most typical variants of mutual arrangement of the local heating source and the reacting substance are analyzed: the hot particle is on the surface of coal layer, and this particle is partially (Fig. 1) or entirely penetrated in its near-surface layer.

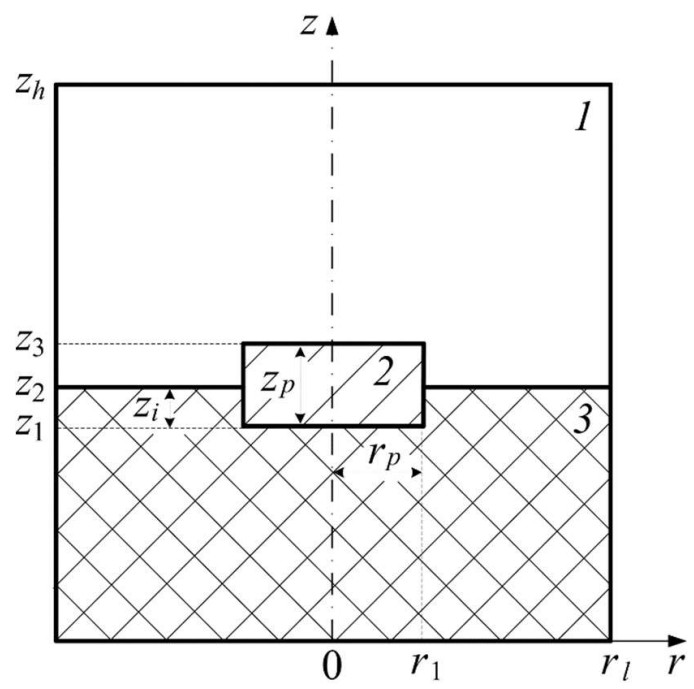

FIGURE 1. Scheme showing the solution of dispersed coal ignition problem under the partial penetration of a hot particle in the near-surface layer: 1 - air, 2 - local heating source, 3 - coal

For the most practically significant and therefore highly representative variant (Fig. 1) the following scheme of the investigated process is adopted. At the initial time, the metal (steel) particle - the ignition source with a temperature $T_{p}$ that is significantly higher than the ambient temperature $T_{0}$, is under the conditions of perfect thermal contact with the coal layer. As a result of conductive heat transfer, the near-surface layer of fuel is warmed up. With the temperature increasing begins the process of intensive thermal decomposition of coal with the expulsion of volatile components. This process is taking place at a maximum rate near the contact boundary of coal with the hot particle, where the temperature reaches 500-600 K. From this region, the gaseous products of thermal decomposition are filtered in the direction of the coal / air boundary and are blown into the environment in small neighborhood of the base of a local heating source. In the conditions of rapid inductive period, the thermal decomposition of coal leads to a decrease in the concentration of the organic part with a constant fuel volume. In gas environment, the combustible mixture is formed by mixing volatiles with air oxygen due to the diffusion. Additional heating of the fuel mixture with the oxidizer occurs when it moves along the side faces of the hot particle until the ignition conditions are reached.

The following conditions are accepted as a criterion of gas-phase ignition $[13,14]$ :

1. The heat released as a result of the oxidation reaction of volatiles is greater than the heat withdrawn from the hot particle (the heating source) into the coal and gas environment.

2. The gas mixture temperature in the zone with intensive oxidation reaction exceeds the temperature of the local heating source.

\section{MATHEMATICAL MODEL AND SOLUTION METHODS}

Mathematical model of the process under study (Fig. 1) is represented by a system of differential equations in partial derivatives with the corresponding initial and boundary conditions.

Heat conduction equation for a mixture of volatiles with the air in the account of exothermic reaction: 


$$
\rho_{1} C_{1} \frac{\partial T_{1}}{\partial t}=\lambda_{1}\left(\frac{\partial^{2} T_{1}}{\partial r^{2}}+\frac{1}{r} \frac{\partial T_{1}}{\partial r}+\frac{\partial^{2} T_{1}}{\partial z^{2}}\right)+Q_{1} \rho_{1} \mu_{v} \mu_{o} k_{1} \exp \left(-\frac{E_{1}}{R_{t} T_{1}}\right)
$$

The equation of diffusion of volatiles in the air:

$$
\frac{\partial \mu_{v}}{\partial t}=D_{1}\left(\frac{\partial^{2} \mu_{v}}{\partial r^{2}}+\frac{1}{r} \frac{\partial \mu_{v}}{\partial r}+\frac{\partial^{2} \mu_{v}}{\partial z^{2}}\right)-\mu_{v} \mu_{o} k_{1} \exp \left(-\frac{E_{1}}{R_{t} T_{1}}\right)
$$

The equation to preserve the concentration of a gas mixture components:

$$
\mu_{v}+\mu_{o}=1 \text {. }
$$

The heat conduction equation for a hot particle:

$$
\rho_{2} C_{2} \frac{\partial T_{2}}{\partial t}=\lambda_{2}\left(\frac{\partial^{2} T_{2}}{\partial r^{2}}+\frac{1}{r} \frac{\partial T_{2}}{\partial r}+\frac{\partial^{2} T_{2}}{\partial z^{2}}\right) .
$$

The heat conduction equation for coal with consideration of thermal decomposition:

$$
\rho_{3} C_{3} \frac{\partial T_{3}}{\partial t}=\lambda_{3}\left(\frac{\partial^{2} T_{3}}{\partial r^{2}}+\frac{1}{r} \frac{\partial T_{3}}{\partial r}+\frac{\partial^{2} T_{3}}{\partial z^{2}}\right)-Q_{3} \rho_{3}\left(1-\eta_{3}\right) k_{3} \exp \left(-\frac{E_{3}}{R_{t} T_{3}}\right) .
$$

The equation of chemical kinetics for coal:

$$
\frac{\partial \eta_{3}}{\partial t}=\left(1-\eta_{3}\right) k_{3} \exp \left(-\frac{E_{3}}{R_{t} T_{3}}\right) .
$$

The thermophysical properties of gas mixture were calculated with consideration of the volume concentrations of components:

$$
\begin{gathered}
\rho_{1}=\rho_{v} \varphi_{v}+\rho_{o} \varphi_{o}, C_{1}=C_{v} \varphi_{v}+C_{o} \varphi_{o}, \lambda_{1}=\lambda_{v} \varphi_{v}+\lambda_{o} \varphi_{o}, \\
\varphi_{v}=\frac{\mu_{v} / \rho_{v}}{\mu_{v} / \rho_{v}+\mu_{o} / \rho_{o}}, \\
\varphi_{v}+\varphi_{o}=1 .
\end{gathered}
$$

The coal density, which varies as a result of thermal decomposition and the yield of volatile components, was calculated with the use of the formula $\rho_{3}=p_{c} \varphi_{c}+p_{v} \varphi_{v}$, the heat capacity and the fuel thermal conductivity were given as functions of temperature [17-19]:

$C_{3}=0.18 \cdot 10^{-3} T_{3}^{2}-0.197 T_{3}+1515, \mathrm{~J} /(\mathrm{kg} \cdot \mathrm{K})$ at $300<T_{3}<1500 \mathrm{~K}$;

$\lambda_{3}=0.075 \cdot 10^{-6} T_{3}^{2}+0.014 \cdot 10^{-3} T_{3}+0.138, \mathrm{~W} /(\mathrm{m} \cdot \mathrm{K})$ at $300<T_{3}<1500 \mathrm{~K}$.

Nomenclature and units: $C$ - heat capacity, $\mathrm{J} /(\mathrm{kg} \cdot \mathrm{K}) ; D$ - diffusion coefficient, $\mathrm{m}^{2} / \mathrm{s} ; E$ - activation energy, $\mathrm{J} / \mathrm{mol}$; $k$ - pre-exponential factor, $1 / \mathrm{s} ; Q_{1}$ - thermal effect of the oxidation reaction of volatiles, $\mathrm{J} / \mathrm{kg} ; Q_{3}$ - thermal effect of the coal thermal decomposition, $\mathrm{J} / \mathrm{kg} ; R_{t}$ - universal gas constant, $\mathrm{J} /(\mathrm{mol} \cdot \mathrm{K}) ; r, z$-coordinates, $\mathrm{m} ; r_{l}, z_{h}$-dimensions of the solution area, $\mathrm{m} ; r_{p}, z_{p}$ - dimensions of the hot particle, $\mathrm{m} ; T$ - temperature, $\mathrm{K} ; T_{0}$ - initial temperature of air and coal, $\mathrm{K} ; T_{p}$ - initial temperature of the hot particle, $\mathrm{K} ; t$ - time, $\mathrm{C} ; t_{d}$ - ignition delay time, s; $\Delta r, \Delta z$ - steps in spatial coordinates, $\mathrm{m} ; \Delta t$ - time step, $\mathrm{s} ; \eta$ - degree of coal thermal decomposition; $\lambda$ - thermal conductivity, $\mathrm{W} /(\mathrm{m} \cdot \mathrm{K})$; $\mu$ - mass concentration; $\rho$ - density, $\mathrm{kg} / \mathrm{m}^{3} ; \varphi$ - volume concentration. Indexes: 1 - gas mixture of volatiles with air; 2 - local heating source; 3 - coal; $c$ - carbon; $o$ - air; $v$ - volatiles.

Initial conditions $(t=0)$ :

air and coal temperature $T_{1}=T_{3}=T_{0}$;

temperature of local heating source $T_{2}=T_{p}$;

mass concentration of components (carbon and volatiles) in coal $\mu_{c}+\mu_{v}=1, \mu_{c}=0.6$;

degree of coal thermal decomposition $\eta_{3}=0$;

mass concentration of volatiles in the gas $\mu_{v}=0$.

Boundary conditions (Fig. 1 ) at $0<t<t_{d}$ : 


$$
\begin{aligned}
& r=0,0<z<z_{1} ; r=r_{l}, 0<z<z_{2} \\
& \frac{\partial T_{3}}{\partial r}=0 \\
& r=0, z_{1}<z<z_{3} \\
& \frac{\partial T_{2}}{\partial r}=0 \\
& r=0, z_{3}<z<z_{h} ; r=r_{l}, z_{2}<z<z_{h} \\
& \frac{\partial T_{1}}{\partial r}=0, \frac{\partial \mu_{v}}{\partial r}=0 ; \\
& r=r_{1}, z_{1}<z<z_{2} \\
& -\lambda_{2} \frac{\partial T_{2}}{\partial r}=-\lambda_{3} \frac{\partial T_{3}}{\partial r}, T_{2}=T_{3} ; \\
& r=r_{1}, z_{2}<z<z_{3} \\
& -\lambda_{2} \frac{\partial T_{2}}{\partial r}=-\lambda_{1} \frac{\partial T_{1}}{\partial r}, T_{2}=T_{1}, \frac{\partial \mu_{v}}{\partial r}=0 ; \\
& z=0,0<r<r_{l} \\
& z=z_{1}, 0<r<r_{1} \\
& z=z_{2}, r_{1}<r<r_{1}+10 \Delta r \\
& \frac{\partial T_{3}}{\partial z}=0 \\
& -\lambda_{3} \frac{\partial T_{3}}{\partial z}=-\lambda_{2} \frac{\partial T_{2}}{\partial z}, T_{3}=T_{2} ; \\
& -\lambda_{3} \frac{\partial T_{3}}{\partial z}+Q_{3} \rho_{3}\left(1-\eta_{3}\right) k_{3} \exp \left(-\frac{E_{3}}{R_{t} T_{3}}\right) \Delta z=-\lambda_{1} \frac{\partial T_{1}}{\partial z}, T_{3}=T_{1}, \\
& -\rho_{1} D_{1} \frac{\partial \mu_{v}}{\partial z}=f(r) \int_{0}^{z_{1}} \int_{0}^{r_{1}} \rho_{3}\left(1-\eta_{3}\right) k_{3} \exp \left(-\frac{E_{3}}{R_{t} T_{3}}\right) d r d z+ \\
& +\int_{0}^{z_{2}} \rho_{3}\left(1-\eta_{3}\right) k_{3} \exp \left(-\frac{E_{3}}{R_{t} T_{3}}\right) d z \\
& -\lambda_{3} \frac{\partial T_{3}}{\partial z}+Q_{3} \rho_{3}\left(1-\eta_{3}\right) k_{3} \exp \left(-\frac{E_{3}}{R_{t} T_{3}}\right) \Delta z=-\lambda_{1} \frac{\partial T_{1}}{\partial z}, T_{3}=T_{1}, \\
& -\rho_{1} D_{1} \frac{\partial \mu_{v}}{\partial z}=\int_{0}^{z_{2}} \rho_{3}\left(1-\eta_{3}\right) k_{3} \exp \left(-\frac{E_{3}}{R_{t} T_{3}}\right) d z \text {; } \\
& z=z_{3}, 0<r<r_{1} \\
& -\lambda_{2} \frac{\partial T_{2}}{\partial z}=-\lambda_{1} \frac{\partial T_{1}}{\partial z}, T_{2}=T_{1}, \frac{\partial \mu_{v}}{\partial z}=0 ; \\
& z=z_{h}, 0<r<r_{l} \\
& \frac{\partial T_{1}}{\partial z}=0, \frac{\partial \mu_{v}}{\partial z}=0
\end{aligned}
$$

For the distribution function of gaseous products of coal thermal decomposition in the vicinity of the hot particle side face at the boundary coal / air the following equation is equitable [20]:

$$
\int_{r_{1}}^{r_{1}+10 \Delta r} f\left(r-r_{1}\right) d r=1 .
$$

The system of equations (1)-(6) with initial and boundary conditions was solved by the finite difference method. Difference analogues of differential equations were solved with the help of locally univariate method. The system of one-dimensional difference equations was solved by iteration and run methods using an implicit four-point difference scheme. The following parameters of spatial and time grids were accepted: steps on spatial coordinates $\Delta r=\Delta z=50 \mu \mathrm{m}$, time step $\Delta t=10 \mu \mathrm{s}$. It is found that the step reduction $\Delta r$ and $\Delta z$ from 100 to $50 \mu \mathrm{m}$ and $\Delta t$ from 20 to $10 \mu \mathrm{s}$ leads to 
a change in the results of mathematical modeling no more than by $0.5 \%$. Checking the conservatism of the used difference scheme allowed us to establish that the error of the energy conservation law in the problem solution area (Fig. 1) does not exceed 1.2\%.

When comparing the results of numerical simulation with the experimental data [11] on the ignition delay times by a steel particle $\left(r_{p}=z_{p}=3 \mathrm{~mm}\right)$ of dispersed brown coal, their satisfactory correlation (Fig. 2$)$ in the initial temperature range of the local energy source $T_{p}=1300-1500 \mathrm{~K}$ was identified. The difference between theoretical and experimental values of $t_{d}$ does not exceed measurement errors [11].

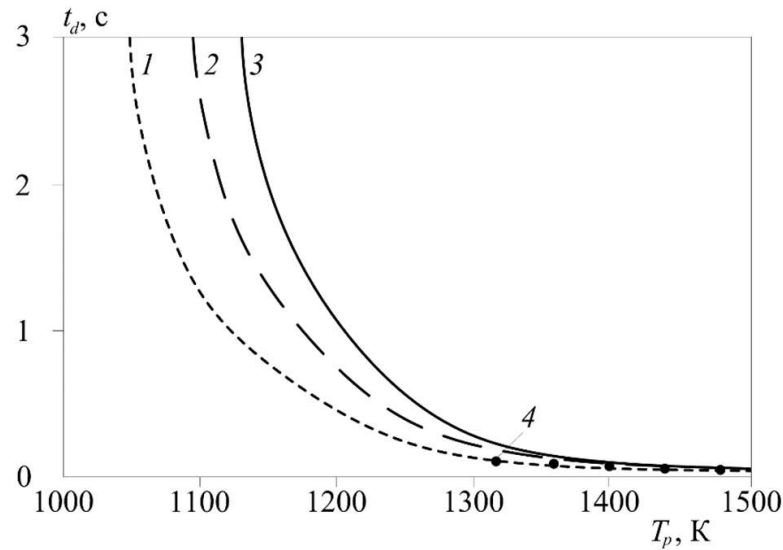

FIGURE 2. Dependences of the delay time of a dispersed coal ignition on the particle initial temperature:

1 - at $\delta=0 ; 2$ - at $\delta=0.5 ; 3-$ at $\delta \rightarrow 1 ; 4$ - experimental data [11]

\section{RESULTS AND DISCUSSION}

The ignition process was simulated at initial temperatures of air and coal $T_{0}=300 \mathrm{~K}$, hot steel particle $T_{p}=1000$ $1500 \mathrm{~K}$. The dimensions of the solution domain (Fig. 1) $r_{l}=z_{h}=20 \mathrm{~mm}$, the sizes of the metal particle $r_{p}=z_{p}=3 \mathrm{~mm}$. Thermophysical properties of substances and effective values of kinetic characteristics of thermal decomposition and oxidation processes [17-19, 21-24]:

$\lambda_{o}=0.026 \mathrm{~W} /(\mathrm{m} \cdot \mathrm{K}), \rho_{o}=1.161 \mathrm{~kg} / \mathrm{m}^{3}, C_{o}=1190 \mathrm{~J} /(\mathrm{kg} \cdot \mathrm{K}) ;$

$\lambda_{2}=49 \mathrm{~W} /(\mathrm{m} \cdot \mathrm{K}), \rho_{2}=7831 \mathrm{~kg} / \mathrm{m}^{3}, C_{2}=470 \mathrm{~J} /(\mathrm{kg} \cdot \mathrm{K}) ;$

$\lambda_{c}=0.149 \mathrm{~W} /(\mathrm{m} \cdot \mathrm{K}), \rho_{c}=1200 \mathrm{~kg} / \mathrm{m}^{3}, C_{c}=1440 \mathrm{~J} /(\mathrm{kg} \cdot \mathrm{K})-$ at $T_{3}=300 \mathrm{~K} ;$

$\lambda_{v}=0.03 \mathrm{~W} /(\mathrm{m} \cdot \mathrm{K}), \rho_{v}=0.5 \mathrm{~kg} / \mathrm{m}^{3}, C_{v}=1132 \mathrm{~J} /(\mathrm{kg} \cdot \mathrm{K}), D_{0}=0.56 \cdot 10^{-4} \mathrm{~m}^{2} / \mathrm{s}$;

$E_{1}=77 \cdot 10^{3} \mathrm{~J} / \mathrm{mol}, Q_{1} k_{1}=5.52 \cdot 10^{11} \mathrm{~J} /(\mathrm{kg} \cdot \mathrm{s})$;

$E_{3}=195 \cdot 10^{3} \mathrm{~J} / \mathrm{mol}, Q_{3} k_{3}=25.5 \cdot 10^{14} \mathrm{~J} /(\mathrm{kg} \cdot \mathrm{s})$.

The problem of numerical analysis of the studied process (Fig. 1) was to identify the effect of depth of a local heating source penetration into the near-surface layer of dispersed coal on the main integral characteristic - the ignition delay time $t_{d}$. The factor determining the intensity of physical and chemical processes (and as a result of $t_{d}$ ) is the heat content of a heating source, which according to the equation $Q_{2}{ }^{0}=\rho_{2} C_{2} V_{2}\left(T_{p}-T_{0}\right)$ [25] is more characterized by its initial temperature $\left(V_{2}\right.$ is heating source volume, $\left.\mathrm{m}^{3}\right)$. Therefore, the numerical study was performed with a variation of $T_{p}$ in the range of $1000-1500 \mathrm{~K}$.

Figure 2 shows the dependence of ignition delay time of dispersed coal from the initial temperature of heating source for several options: the hot particle is located on the surface of the fuel layer $\delta=0$ (curve 1 in Fig. 2) and is partially penetrated in the near-surface layer $\delta=0.5$ (curve 2 in Fig. 2), fully penetrated in the near-surface layer $\delta \rightarrow 1$ (curve 3 in Fig. 2). Here $\delta=z_{i} / z_{p}$ (Fig. 1) is a dimensionless parameter characterizing the depth of penetration.

It was established (Fig. 2), that in conditions of a hot particle penetration into coal layer, the increase of $\delta$ (all other things being equal) leads to a rise in $t_{d}$ and in the limit (minimum) temperature of $T_{p}$, that is necessary to initiate the combustion process. The revealed regularity appears on a larger scale at relatively low $\left(T_{p}<1300 \mathrm{~K}\right)$ initial temperatures of the heating source. For the cases $\delta=0$ and $\delta \rightarrow 1$, the maximum difference between ignition delay times is more than $55 \%$. In this case, the limit value for the ignition of the metal particle initial temperature increases from $1050 \mathrm{~K}$ (curve 1 in Fig. 2) up to $1150 \mathrm{~K}$ (curve 3 in Fig. 2). At relatively high $T_{p}$ (over $1300 \mathrm{~K}$ ) in terms of $t_{d}<0.5 \mathrm{~s}$ the depth of penetration affects much less on the ignition delay times. 
The obtained result can be explained by change in the ratio of surface area of the heating source, from which the heat sink into fuel and gas is carried out when the particle penetrates into a coal layer. With increasing of the penetration depth a proportion of the particle heat that transfers to the solid fuel grows. The local heating source cools down more intensively in comparison with the case $\delta=0$, when the rate of heat transfer to the surrounding gas environment is minimal due to the low thermal conductivity of the air. Although due to the increase in the coal heating surface area the quantity of gaseous products of thermal decomposition grows, however, for a sufficiently long time period (on the scale of the induction period) their temperature in the oxidizing medium, where ignition occurs, is less than the temperature of volatiles under heating conditions, when the hot particle is located on the surface of a fuel layer. With the partial penetration of a local heating source into the coal, a large proportion of the thermal decomposition products (the combustible component of the gas mixture) is formed under the particle. Filtration of volatiles through the coal layer to the border with the environment of an oxidant (Fig. 1) occurs at a significantly lower rate in comparison with the movement conditions of gaseous products of fuel decomposition with the scheme of heating by a particle located on the surface of fuel. The subsequent heating of volatiles in the gas mixture until the ignition moment is realized when it moves along the side face of the particle. Due to the decreasing of heating surface area of fuel-oxidizer mixture owing to the local source penetration in a layer of dispersed coal, the threshold ignition temperatures are not reached due to the decrease in heating time of combustible gases. If ignition occurs in the conditions of particle penetration, the induction period increases, because the increase in inflow of gaseous decomposition products leads to more intensive cooling of the particle by them. As a result, the combustible gases must travel a greater distance along a side face of the particle to warm up to temperatures corresponding to the ignition conditions.

Temperature distribution in the problem solution area at the ignition time (Fig. 3) illustrates that along with the initial temperature of a hot particle (similar to [15]), the depth of its penetration into the near-surface layer of coal also affects the zone location (the area is depicted by a dashed line in Fig. 3) of the leading oxidation reaction in the gas mixture. The reason for this is largely characterized by the intensity of cooling of the local heating source during the heating process of solid fossil fuel. Three characteristic modes have been revealed. At relatively low $\delta$ (less than 0.2 ), the initial temperature of the source during the induction period decreases by $20-30 \mathrm{~K}$ and the ignition is realized in the vicinity of the coal / air boundary (Fig. 3a). With the growth of $\delta$ (more than 0.2 ) the decrease in $T_{p}$ by the 30$50 \mathrm{~K}$ and reduction of heat flux in the gas leads to a shift of ignition zone (Fig. $3 b$ ) in the movement direction of coal thermal decomposition products. At $\delta>0.5$, the decrease in hot particle temperature in comparison with the initial value due to the heat sink into loose coal can reach $100 \mathrm{~K}$, while the gas mixture ignition is realized over the particle already (Fig. 3c). 


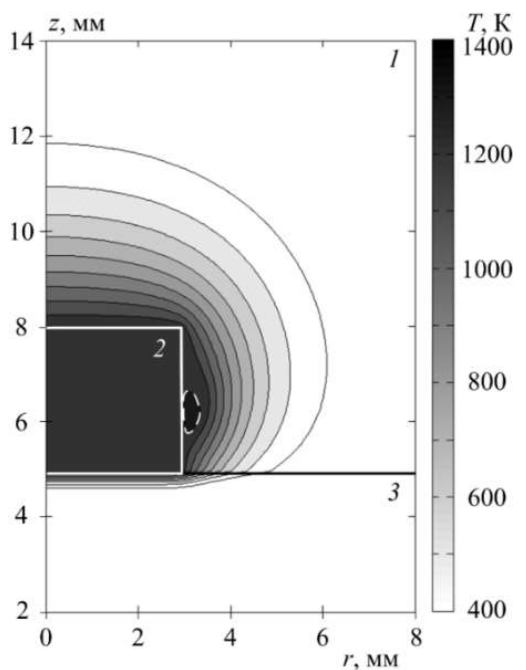

(a)

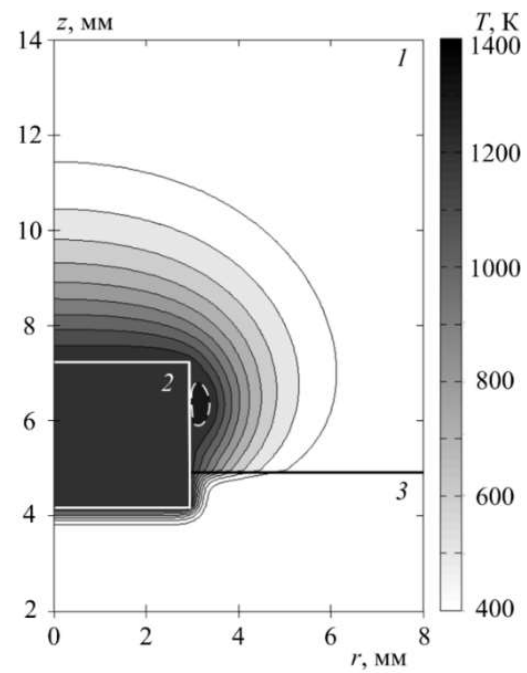

(b)

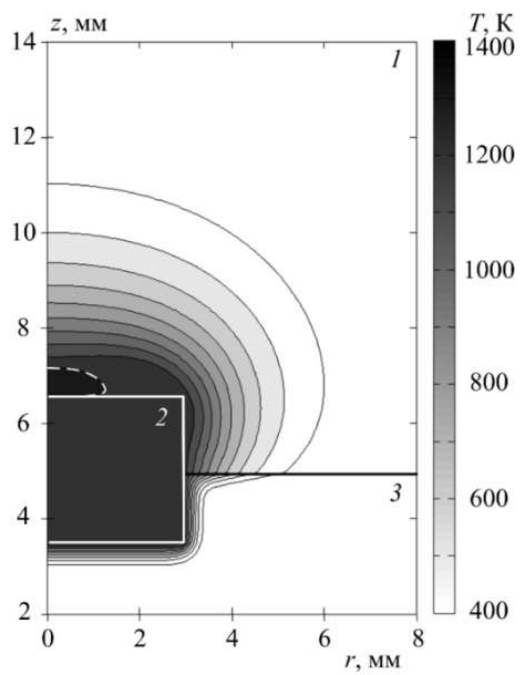

(c)

FIGURE 3. Isotherms $(T, \mathrm{~K})$ at the moment of ignition of dispersed coal at different depth of penetration of a hot particle $\left(T_{p}=1300 \mathrm{~K}\right)$ in a near-surface layer: (a) $t_{d}=0.137 \mathrm{~s}$ at $\delta=0 ;(b) t_{d}=0.196 \mathrm{~s}$ at $\delta=0.25$; (c) $t_{d}=0.219 \mathrm{~s}$ at $\delta=0.5$

According to the results of numerical simulation it was established that ignition of typical brown coal is possible at the deposition of a hot (temperature more than $1000 \mathrm{~K}$ ) small-sized particle (some millimeters in size) on a layer surface of the dispersed fuel. The analysis allows us to conclude that at relatively low initial temperatures $\left(T_{p}<1100 \mathrm{~K}\right)$ of the particle with an increase in the depth of its penetration into the coal surface layer, the probability of fulfilling the ignition conditions decreases. In the conditions when $T_{p}>1300 \mathrm{~K}$ and $t_{d}<0.5 \mathrm{~s}$ the influence of penetration depth of the local heating source on the characteristics of the initiation process can be reasonably neglected.

\section{CONCLUSION}

As a study result of the dispersed coal ignition by a particle heated to high temperatures, it was found that the increase in the depth of penetration of a local heating source into the near-surface layer of solid natural fuel leads to an increase in the ignition delay time and to the minimum temperature of the hot particle required to initiate combustion. On a larger scale, this factor is manifested at relatively low $\left(T_{p}<1300 \mathrm{~K}\right)$ initial temperatures of the heating source. For the cases $\delta=0$ and $\delta \rightarrow 1$, the maximum difference between the ignition delay times is more than $55 \%$, and 
the minimum value of the initial temperature of a hot particle for ignition increases from 1050 to $1150 \mathrm{~K}$. At relatively high $T_{p}$ of the source (more than $1300 \mathrm{~K}$ ) when $t_{d}<0.5 \mathrm{~s}$, the depth of penetration into the near-surface layer has a significantly smaller effect on the ignition delay times.

It was also found that the penetration depth of the hot particle along with its initial temperature affects the leading area of the oxidation reaction in the gas. Three ignition modes of fuel, characterized by the location of ignition zone in the gas environment, are revealed: on the coal / air border, near the side face of the heating source and above the particle.

\section{ACKNOWLEDGMENTS}

Study was financially supported by the Grant of the President of the Russian Federation (project no. MK2454.2018.3).

\section{REFERENCES}

1. T. S. Yusupov, L. G. Shumskaya, A. P. Burdukov and V. A. Logvinenko, Khimiya v interesakh rassmotreniya razvitiya 4, 427-432 (2011) [in Russian].

2. A. A. Vasil'yev, A. V. Pinaev, A. A. Trubitsyn, A. U. Grachev, A. V. Trotsyuk, P. A. Fomin and A. V. Trilis, Combust. Explos. Shock Waves 53 (1), 11-18 (2017).

3. S. V. Alekseenko, A. P. Burdukov, G. V. Chernova and V. N. Churashev, Izvestiya Akademii Nauk. Energetika 2, 52-63 (2003) [in Russian].

4. P. N. Kuznetsov, Solid Fuel Chem. 4 (6), 329-333 (2013).

5. S. P. Amel'chugov, V. I. Bykov and S. B. Tsybenova, Combust. Explos. Shock Waves 38 (3), $295-300$ (2002).

6. A. I. Kamneva, Solid Fuel Chemistry 2, 68-74 (1971) [in Russian].

7. N. M. Kachurin, A. U. Ermakov, V. I. Efimov and A. V. Wahlberg, bezopasnost' truda v promyshlennosti 3, 4446 (2016).

8. K. A. Joshi, V. Raghavan and A. S. Rangwala, Combust. Flame 159 (1), 376-384 (2012).

9. A. Janes, D. Carson, A. Accorsi, J. Chaineaux, B. Tribouilloy, D. Morainvillers and J. Hazard, Mater. 159, 528535 (2008).

10. A. V. Zakharevich and A. R. Bogomolov, Russ. J. Phys. Chem. B 9 (6), 907-910 (2015).

11. A. V. Zakharevich and V. N. Ogorodnikov, Pozharovzryvobezopasnost' 22 (3), 13-19 (2013) [in Russian].

12. G. V. Kuznetsov, G. Ya. Mamontov and G. V. Taratushkina, Khimicheskaya Fizika 23 (3), 67-72 (2004) [in Russian].

13. D. O. Glushkov, G. V. Kuznetsov and P. A. Strizhak, Russ. J. Phys. Chem. B 8 (5), 664-671 (2014).

14. D. O. Glushkov, G. V. Kuznetsov and P. A. Strizhak, Combust. Explos. Shock Waves 53 (2), 1-10 (2017).

15. D. O. Glushkov, G. V. Kuznetsov and P. A. Strizhak, Russ. J. Phys. Chem. B 7 (3), 269-275 (2013).

16. A. S. Zavorin, A. Yu. Dolgikh, V. V. Salomatov, S. Batmunkh and Kh. Enkhzhargal, Vestnik Tomskogo politekhnicheskogo universiteta 324 (4), 47-53 (2014) [in Russian].

17. A. A. Agroskin, V. B. Gleybman, Teplofizika tverdogo topliva (Nedra, Moscow, 1980), p. 256 [in Russian].

18. A. A. Agroskin and Ye. I. Goncharov, Koks i khimiya 7, 8-13 (1965) [in Russian].

19. A. A. Agroskin, Ye. I. Goncharov, V. M. Tyagunov, I. G. Zubin and V. B. Gleybman, Koks i khimiya 8, 12-15 (1977) [in Russian].

20. S. Wang, H. Chen, N. Liu and J. Hazard. Mater. 283, 536-543 (2015).

21. N. B. Vargaftik, Y. K. Vinogradov and V. S. Yargin, Handbook of Thermophysical Properties of Liquids and Gases (Begell House, New York, 1996), p. 1358.

22. V. S. Chirkin, Teplofizicheskiye svoystva materialov. Spravochnik (Fizmatlit, Moscow, 1959), p. 356 [in Russian].

23. E. A. Boiko, D. G. Didichin, P. V. Shishmarev, Solid Fuel Chem. 38 (3), 1-9 (2004).

24. P. A. Mar'yandyshev, A. A. Chernov, V. K. Lyubov, Bulletin of the Northern (Arctic) Federal University. Series: Natural sciences 2, 118-128 (2015).

25. S. S. Kutateladze, Fundamentals of the Theory of Heat Transfer (Atomizdat, Moscow, 1979), p. 416 [in Russian]. 